\title{
Digital Construction of Traditional Baruk in Sarawak, Malaysia
}

\author{
Nik Umar Solihin Nik Kamaruzaman¹, Afiqah Ahmad', Norlina Mohamed Noor ${ }^{2}$ \\ ${ }^{1}$ Faculty of Architecture, Planning \& Surveying, ${ }^{2}$ Faculty of Business \& Management, \\ Universiti Teknologi MARA, Cawangan Sarawak, 94300,Kota Samarahan, Sarawak \\ nikumar@uitm.edu.my, afiqa627@uitm.edu.my, norli517@uitm.edu.my \\ Tel: 082677677
}

\begin{abstract}
The traditional Baruk in Sarawak has gone through some architectural changes in terms of its material and function due to the urban modernization and safety concern. Therefore, the research aims to construct the Three-Dimensional (3D) model of the building using digital close-range photogrammetry. The exploratory study can be categorized into four phases consist of Site Selection; Data Acquisition; Data Processing; and 3D Modelling. The 3D model generated from the photogrammetry software presents the result of the dense point clouds. The study could give fundamental guidelines on using a mobile device in digital close-range photogrammetry techniques.
\end{abstract}

Keywords: Digital construction; traditional architecture, digital close-range photogrammetry, heritage documentation

eISSN: 2398-4287@ 2020. The Authors. Published for AMER ABRA cE-Bs by e-International Publishing House, Ltd., UK. This is an open access article under the CC BYNC-ND license (http://creativecommons.org/licenses/by-nc-nd/4.0/). Peer-review under responsibility of AMER (Association of Malaysian Environment-Behaviour Researchers), ABRA (Association of Behavioural Researchers on Asians) and cE-Bs (Centre for Environment-Behaviour Studies), Faculty of Architecture, Planning \& Surveying, Universiti Teknologi MARA, Malaysia.

DOI: https://doi.org/10.21834/ebpj.v5i14.2243

\subsection{Introduction}

The Borneo region is well known for its vast collection of traditional houses that contains a valuable and rich history. In Sarawak, specifically, the buildings were originated from a different group of Dayak community (Iban, Bidayuh \& Orang Ulu), each having a different method of building construction. Among the indigenous group, the Bidayuh people are notable for their traditional Baruk. Historically, the building has become an identical landmark; known as a sacred area for the tribal group (Atar et al., 2018). The architectural form of this building differs from the typical longhouses as it has several unique characteristics such as its octagonal form and the pointed conical roof, which makes it visible from afar. By sitting on the high pillars, it plays a vital role as a watching tower during the times of war. Besides, with its large and circular space, it was used as a gathering area; providing a social interaction between the villagers. As for the building materials, the wall was made from the local timber while the palm thatch is covering the roof structure (Figure 1). From all of the points mentioned, it is important to state that those prominent features have provided a sense of identity to the tribe. Unfortunately, nowadays, the Baruk has gone through some architectural changes in terms of its material and function due to the urban modernization and safety concern. Given that the cultural buildings are currently facing a different form of threats (Mahayuddin et al., 2017), it needs to be securely archived to avoid its disappearance from the cultural landscape of Sarawak. The identity of the place should be kept as much possible to provide a remarkable experience to the outsiders (Ginting \& Rahman, 2016). Therefore, recognizing the growth of digital documentation, this research aims to construct the Three-Dimensional (3D) model of the traditional Baruk using digital close-range photogrammetry (DCRP) application. As the laser scanning method is highly expensive, and the professional camera is often heavy, the research, more specifically explored the uses of mobile devices to reduce the cost, saving acquisition time and providing a lightweight process during the terrestrial survey.

eISSN: 2398-4287@ 2020. The Authors. Published for AMER ABRA cE-Bs by e-International Publishing House, Ltd., UK. This is an open access article under the CC BYNC-ND license (http://creativecommons.org/licenses/by-nc-nd/4.0/). Peer-review under responsibility of AMER (Association of Malaysian Environment-Behaviour Researchers), ABRA (Association of Behavioural Researchers on Asians) and cE-Bs (Centre for Environment-Behaviour Studies), Faculty of Architecture, Planning \& Surveying, Universiti Teknologi MARA, Malaysia.

DOI: https://doi.org/10.21834/ebpj.v5i14.2243 


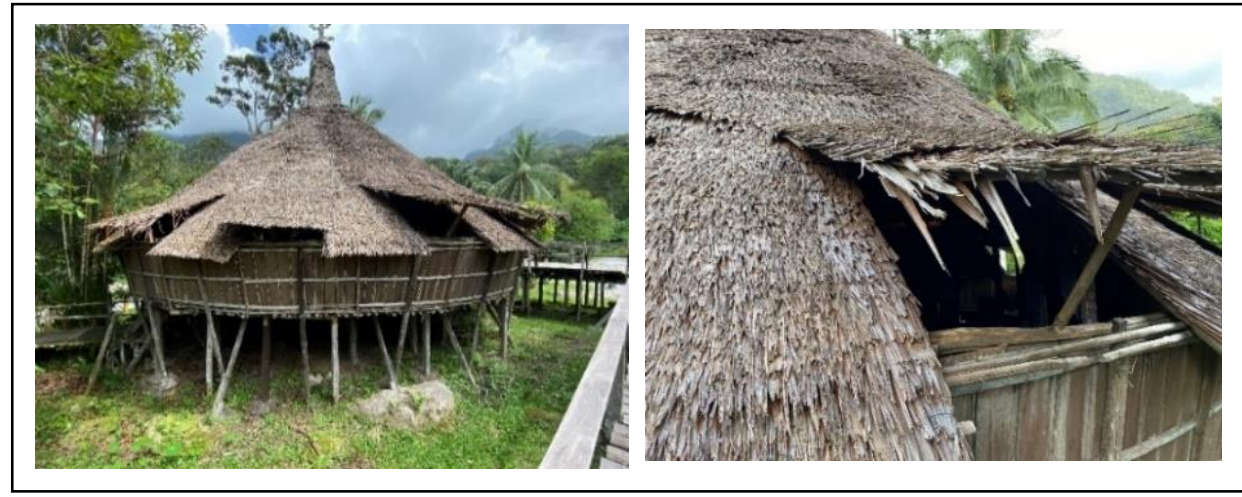

Fig. 1: Traditional Baruk in Sarawak (Source: Author:)

\subsection{Photogrammetry}

\subsection{Digital Close Range Photogrammetry}

In a recent study conducted by Sharif et al. (2018), photogrammetry is defined as the work of using overlapping photos to recreate and reconstruct a 3D model. It is a process of generating geometric data of an object through photographs (Klein et al., 2012), while providing a variety of information such as point clouds and the geometry of an object (Hanan et al., 2015). The scientific fields such as construction, geography, medical and arts, use the technique to solve some of the crucial issues in their sectors. It helps the industries to look into a new possibility as it can provide an accurate visual information. Contrary to the traditional method (manual measurement), digital closerange photogrammetry (DCRP) has become a much desirable option in preserving cultural buildings as it can reduce the cost, time, and has the capabilities to provide accurate visual information. With these benefits, as mentioned by Karabörk et al. (2015), the process of the survey will be short while maintaining a safe work environment. Additionally, information collected from this process will be able to create animated views of the buildings and their surrounding context, allowing local communities to exchange the stories and cultural values (Hanan et al., 2015).

In contemporary practice, the workflow of photogrammetry involves several phases; and it usually starts with data acquisition (Grunova \& Pisca, 2019; Sharif et al., 2018; Faltýnová et al., 2016; Hanan et al., 2015; Karabörk et al., 2015). At this stage (fieldwork), a digital camera will capture the surfaces of the selected object, acquired from a different point of views. Taking the photographs at various angles is indeed crucial to obtain a successful result. The next step refers to data processing; the photogrammetry software will load the photos from the previous fieldwork. The bundle of photos will be aligned, creating the dense point clouds and later on transform into a mesh and textured model. Although this technique can provide faster acquisition, the point cloud production process is slower than a laser scan (Faltýnová et al., 2016). Another limitation is that, for a quality result, the terrestrial work has to be done during cloudy days to avoid shiny and reflective surfaces.

\subsection{Close Range Photogrammetry using Mobile Device}

Recently, the advent of the camera in mobile devices make it possible to reconstruct the geometry of an object by using image sequences technique, allowing the public to become involved in digital heritage documentation. The approach represents a new concept within the photogrammetry industry, and it has the potential to benefit different parties such as the conservators, surveyors, and engineers. A detailed review of this approach can be found in related works by Russo et al. (2019), Gaiani et al. (2019) and Abed et al. (2017).

The study done by Russo et al. (2019) aims to verify the possibility of using a smartphone in Cultural Heritage. For that reason, the scholars surveyed a church façade in Rome to evaluate the performance. The work involves several stages; started with data acquisition and followed by data processing. The results, later on, were compared with the application using a laser scan. It was concluded that using a smartphone for digital photogrammetry provides an easy setup and reducing acquisition time. The study discussed that it is possible to use the portable device for the restoration of a building façade, obtaining the reliable point cloud.

One more case describes the workflow of using a mobile device to capture reliable colour texture of cultural assets (Gaiani et al., 2019). The authors argued that the quality of the image produced by a smartphone able to reach the level of professional equipment. The research attempted to explain the colour accuracy of texture models acquired from the Apple iPhone $X$, which beneficial to the museum management area. Apart from that, Torresani \& Romandino (2019) presents the potential of using videos from a smartphone for heritage documentation. The results showed that the process (extracting video frames) was able to match the point clouds of images from a reflex camera. The researchers believed that the pipeline could be a valuable option for a non-expert to be involved and use the application for a digital reconstruction process.

The last example refers to the modelling of Tel Harmel in Baghdad and the Iraq monument (Abed et al., 2017). The process started with capturing the images of the selected studies using a digital camera and a low-cost smartphone. The acquired images were used to reconstruct the 3D models using Agisoft Photoscan (commercial photogrammetry software). The clouds generated by the software were then compared to evaluate the accuracy of each device. From the findings, it can be concluded that a digital camera can provide a quality result but higher in cost and processing time. Although the usage of smartphone lessens the accuracy, it is still acceptable in terms of reducing the cost and minimize the processing time. As the research into this topic has been growing in recent years, this study 
attempted to use a similar approach to record the cultural building.

\subsection{Methodology \& Results}

The exploratory study can be categorized into four phases consist of Site Selection; Data Acquisition; Data Processing; and 3D Modelling

\subsection{Site Selection}

As a pilot project, DCRP using a portable device was applied to reconstruct the 3D model of the traditional Baruk at Sarawak Cultural Village (SCV). It was selected as it has similar and identical features as the original Baruk in Bau district. This research only focuses on one case study; SCV, due to the location and accessibility factor at that time. The place is currently used as a tourist attraction, exhibiting the traditional dwellings of the indigenous group. The form of the building, as previously described, is circular, structurally made by timber, and it has a conical roof covered with palm thatch (Figure 1).

\subsection{Data Acquisition}

The purpose of the fieldwork is to capture the building's main features (façade) using a mobile device. It is necessary to document the façade of the building as the exterior can provide various visual perspectives (Kaewpeela et al., 2020). The process uses iPhone 11 Pro with its ultra-wide-angle camera option for taking multiple photos of the surface. The key factor of choosing this device is the threecamera option (ultra-wide, wide and telephoto) equipped with advanced features and capabilities. Table 1 presents the specifications of the iPhone 11 Pro. Additionally, a portable tripod was used for this process to assist the operation. The setting for the image was JPEG/ H.264, which is the most compatible setting. (4032 x 3024: image resolution).

\begin{tabular}{|c|c|}
\hline & iPhone 11 Pro \\
\hline Operating System & iOS 13 \\
\hline Chip & $\begin{array}{l}\text { A13 Bionic Chip } \\
\text { 3rd Generation Neural Enqine }\end{array}$ \\
\hline Camera & $\begin{array}{l}\text { 12 MP Ultra Wide } \\
\text { - } \quad 13 \mathrm{~mm} \text { focal length } \\
\text { - } \quad \text { f/2.4 aperture } \\
-\quad 120 \text { field of view } \\
\text { - } \quad 5 \text {-element lens }\end{array}$ \\
\hline
\end{tabular}

(Source: Apple Inc.)

In this proposed workflow, the survey started by establishing the perimeter of the targeted object. The camera placement is an essential factor for the accuracy of the result. Hence, the images must be taken in multi-position and angles to achieve the overlapping effect (Figure 2). However, due to the presence of the natural landscape and artificial obstacles, it is difficult to achieve a good position for the camera station. For this reason, and also due to the limited time and resources, the study did not try to cover the whole building. Instead, the survey was focusing on the half part of the selected case study. Furthermore, to avoid any interference between the survey process and tourist passage, the fieldwork has been planned during the less activities hours.

Taking into consideration the fundamental rules of photogrammetry (Sharif et al., 2018), the captured photographs must be a) overlapped no fewer than $60 \%$ b) the camera must be kept at a consistent distance for each shot and c) the camera has to be perpendicular to the subject. The camera captures the photos at a close range. The survey considered a constant distance of about 2 $\mathrm{m}$ between the camera and the building. The images were taken with a distance of $1.5 \mathrm{~m}$ along the vertical direction to ensure consistency of the information (started from $1 \mathrm{~m}$ above the ground level). Meanwhile, for horizontal direction, the paths were fixed at 2 m distance.

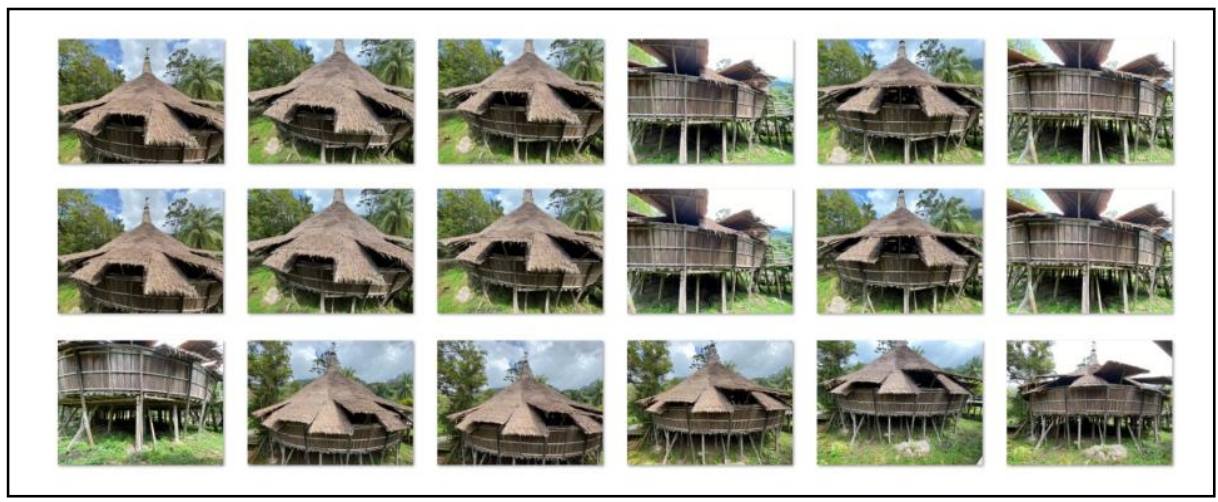

Fig. 2: Photos taken in multi-position for overlapping effect (Source: Author:) 


\subsection{Data Processing}

The acquired images were imported into the Agisoft Metashape (photogrammetric modelling software) for data processing, and it was conducted using a basic workflow. The software is widely used in many different fields as it is well known for its affordable price and the ability to deliver quality results. As such, this helps the researcher to evaluate the performance of DCRP with ease. A computer with the following specifications were used for the image processing:

- $\quad$ Processor: Intel囚 Core ${ }^{\mathrm{TM}}$ i5-8250U CPU @ 1.60GHz

- $\quad$ Memory: RAM 8GB

- $\quad 64$ bit system Windows 10

\subsubsection{Photos Alignment}

A total of up to 180 unedited photos were loaded into the software (Agisoft Metashape). For the alignment parameters, the "high" option was selected, and the key point limit was set to 100,000 while the tie point limit is 10,000. At this stage, the software will first align the photos and determines the position of the camera and create a point cloud (Abed et al., 2017). All of the 180 images were successfully aligned. As shown in Figure 3 (b), removing unnecessary points (surrounding context) will help to reduce the computational processing time (using the rectangle, circle, and free-form selection tool).

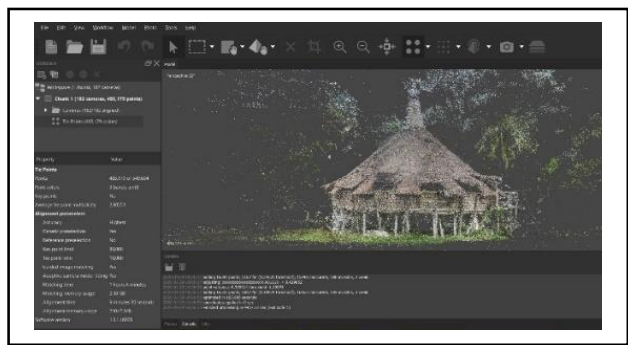

(a)

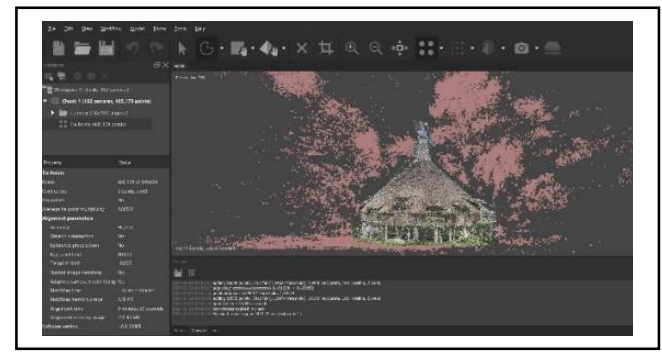

(b)

Fig. 3. (a) Point clouds in Agisoft Metashape; (b) Removing unwanted points.

(Source: Author)

\subsubsection{Generating Dense Point Cloud}

The aligned images, then, created a dense point clouds (.ply format). The "High" option was used for the quality level and moderate option for depth filtering. Table 2 presents the results of the process.

\begin{tabular}{|c|c|c|c|c|}
\hline Image Resolution & Images & Aligned Images & Dense point cloud & Computational time \\
\hline $4032 \times 3024$ & 180 & 180 & $46,252,407$ & $4 \mathrm{~h} 22 \mathrm{~m}$ \\
\hline
\end{tabular}

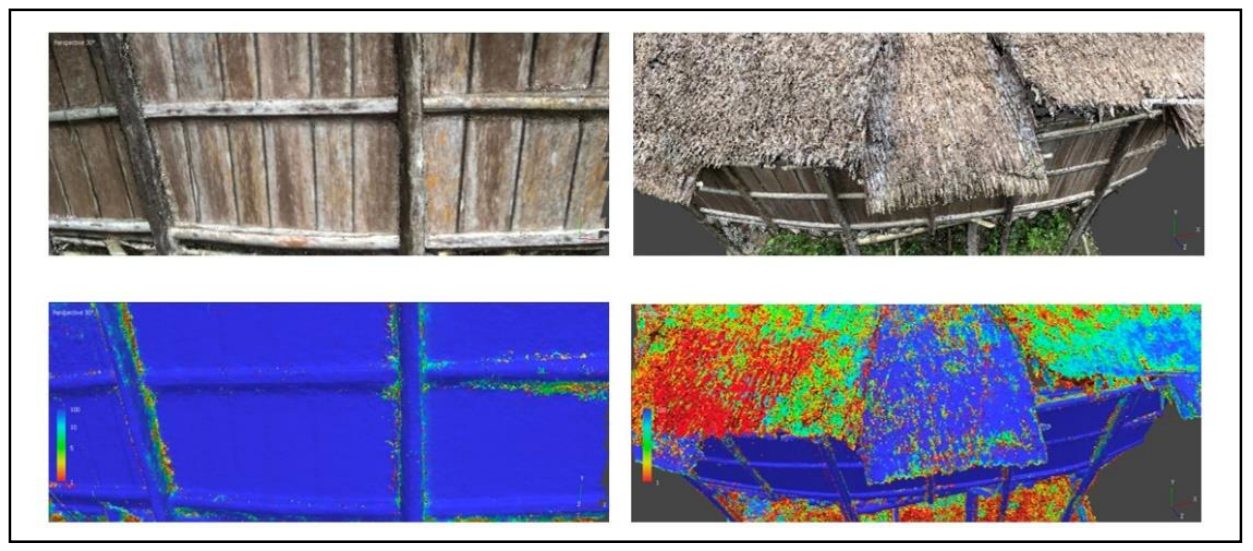

Fig. 4: Results of the model dense cloud (Source: Author)

The confidence mode was analyzed to evaluate the quality of the dense cloud (Figure 4). Based on the result, it can be seen that the model presents different accuracy between the building components. The limitation of this method is that the mobile device could not reach the upper area of the building. Consequently, the dense cloud of the roof has a lower quality compared to the timber wall (ground area). Thus, for future research, the assistance of Unmanned Aerial Vehicle (UAV) would be needed to cover the inaccessible locations. 


\subsection{Three Dimensional Modelling}

\subsubsection{Mesh, Texturing \& Modelling}

The program creates a three-dimensional polygonal mesh representing the surface of the object. Once the processing is complete (including removing the unwanted noise), the file can be exported in various formats such as Wavefront (.obj) and Collada (.dae). Such formats offer various options for 3D modelling. The textured model, for example, can be transferred into Blender (free source software) for the final adjustment and documentation (Sharif et al., 2018). For proper documentation, building components of the model may be categorized into substructure, wall, roof, and details.

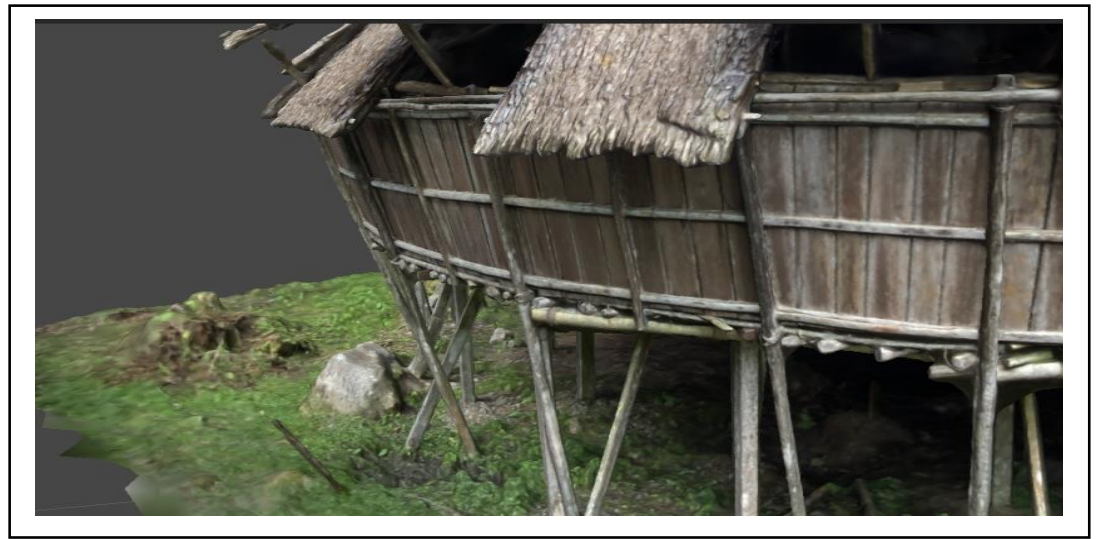

Fig. 5: Textured model of the Traditional Baruk (Source: Author)

Alternatively, the developed 3D model could potentially be used for augmented reality (Azmin et al., 2017). It is essential, in the academic world nowadays to have a digital application for the students to learn. By having a model in a digital context, the students will be able to study the historical features of the traditional building, using an online application. Since the students are towards using their smartphone in search of knowledge (Sabron et al., 2020), augmented reality is the best approach for them to learn. To sum up, the proposed workflow consists of four phases; Site Selection; Data Acquisition; Data Processing and 3D Modelling. Figure 4 presents the workflow of all of these processes.

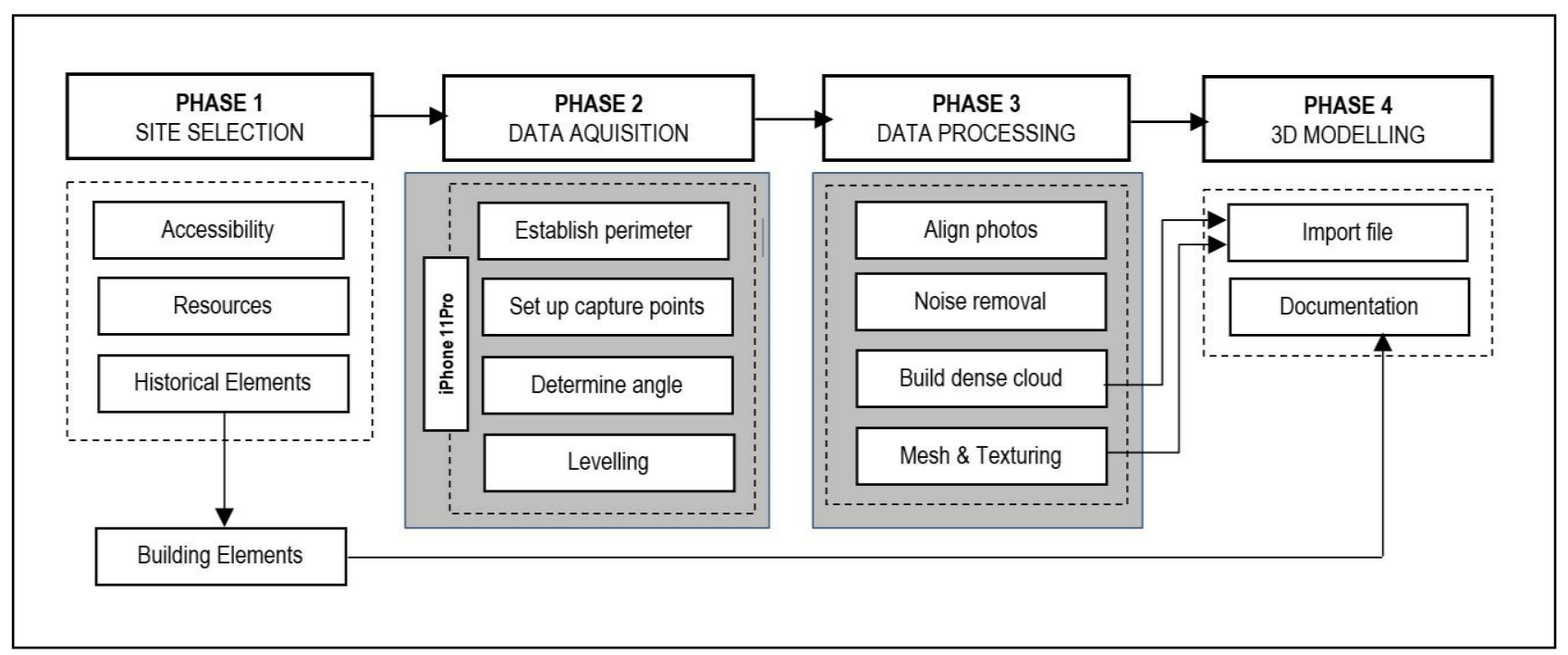

Fig. 5: The workflow of the process

(Source: Author)

\subsection{Discussion}

From the results, it can be seen that using a mobile device is an alternative to produce a $3 \mathrm{D}$ model of an object. The research provides adequate guidelines and framework for a portable digital photogrammetry. Additionally, the research had beneficially decreased the acquisition time and provide a lightweight process. This is crucial because most of the traditional buildings, especially in Sarawak, are located in a rural area; a lightweight survey will make the process easier. 
The benefit of having 3D traditional buildings is the opportunity to apply it to many fields. In a learning environment, for example, the usage of augmented reality will be beneficial to the students during the online class. The approach could foster the student's capability in using digital applications, which is essential to the industry nowadays. Two-dimensional drawings may be insufficient to understand the character of a building. Therefore, a 3D model of traditional building, complete with heritage information, may solve the problems. (Hanan et al., 2015).

However, there are limitations during the process. The first problem found by the researchers was the process could not provide the interior information of the buildings. As such, additional research is needed to explore a suitable method in creating the inner parts of the building (using portable photogrammetry application) to provide a decent building plan. The second limitation was during data collection (fieldwork). Due to the presence of natural landscape and artificial obstacles, the quality of the captured surfaces is lost and missing; specifically, in the upper area of the building (Figure 4). For this reason, further studies must be conducted to improve the quality of the image to provide a better dense point cloud and 3D model. Several recommendations have been identified to increase the situation, such as:

- The camera needs to be calibrated and set to manual setting (using a third-party app) to control the focus and the exposure value, ensuring the consistency of the image.

- The assistance of Unmanned Aerial Vehicle (UAV) to cover the upper part of the buildings and inaccessible locations (Grunova \& Pisca, 2019). The usage of drones can help to provide close up images of the selected buildings.

- Image pre-processing should be done to avoid loss of information. The works include colour balancing, exposure equalization, image de-noising, colour to grey and image content enhancement. (Gaiani et al., 2016).

- Comparing the quality of the point clouds among different equipment and tools (professional camera or laser scanner) to assess the accuracy of the proposed workflow. (Russo et al., 2019; Abed et al., 2017).

\subsection{Conclusion}

This paper presents the guidelines and results of using a mobile device in a DCRP application. It aims to restore the Traditional Baruk in a digital environment using portable equipment. The developed pipeline consists of Site Selection; Data Acquisition; Data Processing; and 3D Modelling. The 3D model generated from the photogrammetry software presents the result of the dense point clouds. The study could give fundamental guidelines on using a mobile device in digital close-range photogrammetry techniques.

Although the result of the study shows that currently, the accuracy does not meet the requirements for some applications of DCRP, there are several opportunities to further deepen the research in the future. The main advantages highlighted by this study is that a) the process can be done in a short period and $b$ ) having a lightweight process during the terrestrial survey. The researchers believed that the study provides flexibility in data collection as the smartphone can be conducted by almost anyone. Apart from that, as mentioned earlier, DCRP delivers a variety of data, allowing indigenous communities to share their culture and stories. This is important because indigenous students need to develop a sense of belonging (similar context) to excel in the educational system. (Aziz et al., 2020)

As for the future research, a systematic documentation must be established to ensure the knowledge of the traditional construction can be distributed to the new generations (Ali et al., 2018) and provide a better understanding of its cultural architecture. Proper documentation is needed for the current usage of building performance. As Building Information Modelling (BIM) is well known for building documentation, further studies will be conducted to document the traditional building in a BIM environment. In this regard, Historic Building Information Modelling (HBIM) will be looking into detail to produce a complete heritage database (Banfi, 2020; Sztwiertnia et al., 2019) and manage the public participation in historical buildings. (Salvador-García et al., 2020). Recognizing the benefits of HBIM (Kamaruzaman, 2019), the authors believed that this new approach will help to improve society's knowledge of traditional buildings in Malaysia.

\section{Acknowledgements}

The authors would like to express their appreciation to Dana Kecemerlangan UiTM Sarawak, for funding this project and the research was possible through support from the Sarawak Cultural Village.

\section{References}

Abed, F. M., Mohammed, M. U., \& Kadhim, S. J. (2017). Architectural and Cultural Heritage conservation using low-cost cameras. Applied Research Journal, 3, 376-384. Agisoft Metashape. (2020). 3D model reconstruction. Retrieved from https://www.agisoft.com/

Ali, M., Ismail, K. M., Hashim, K. S. H. Y., Suhaimi, S., \& Mustafa, M. H. (2018). Heritage Building Preservation Through Building Information Modelling: Reviving Cultural Values Through Level of Development Exploration. PLANNING MALAYSIA, 16(6).

Apple Inc. (2019). IPhone 11 Pro: Tech Specs. Retrieved from https://www.apple.com/my/

Atar, S. A., Ansely, A., \& Bala, B. (2018). Fungsi dan Cabaran Baruk Sebagai Warisan Budaya Bidayuh. Jurnal Borneo Arkhailogia (Heritage, Archaeology and History), (1), 97-122.

Aziz, N. A. A., Ariffin, N. F. M., Ismail, N. A., \& Alias, A. (2020). The Significance of Living Heritage Conservation Education for the Community toward Sustainable Development. Environment-Behaviour Proceedings Journal, 5(13), 125-131. 
Azmin, A. K., Kassim, M. H., Abdullah, F., \& Sanusi, A. N. Z. (2017). Architectural heritage restoration of Rumah Datuk Setia via mobile augmented reality restoration. Planning Malaysia, 15(1).

Banfi, F. (2020). HBIM, 3D drawing and virtual reality for archaeological sites and ancient ruins. Virtual Archaeology Review.

Faltýnová, M., Matoušková, E., Šedina, J., \& Pavelka, K. (2016). BUILDING FACADE DOCUMENTATION USING LASER SCANNING AND PHOTOGRAMMETRY AND DATA IMPLEMENTATION INTO BIM. International Archives of the Photogrammetry, Remote Sensing \& Spatial Information Sciences, 41.

Gaiani, M., Apollonio, F. I., \& Fantini, F. (2019). EVALUATING SMARTPHONES COLOR FIDELITY AND METRIC ACCURACY FOR THE 3D DOCUMENTATION OF SMALL ARTIFACTS. International Archives of the Photogrammetry, Remote Sensing \& Spatial Information Sciences.

Gaiani, M., Remondino, F., Apollonio, F. I., \& Ballabeni, A. (2016). An advanced pre-processing pipeline to improve automated photogrammetric reconstructions of architectural scenes. Remote Sensing, 8(3), 178.

Ginting, N., \& Rahman, N. V. (2016). Preserve urban heritage district based on place identity. Asian Journal of Environment-Behaviour Studies, 1(1), 67-77.

Grunova, Z., \& Pisca, P. (2019, November). Progressive Non-Destructive Digital Methods in the Research of Small Sacral Architecture in Czech and Slovak Republic. In IOP Conference Series: Materials Science and Engineering (Vol. 661, No. 1, p. 012092). IOP Publishing.

Hanan, H., Suwardhi, D., Nurhasanah, T., \& Santa Bukit, E. (2015). Batak Toba cultural heritage and close-range photogrammetry. Procedia-Social and Behavioral Sciences, 184, 187-195.

Karabörk, H., Karasaka, L., \& Yaldı, E. (2015). A case study: Documentation method with close range photogrammetry of muqarnas which is to be an ornamentation type specific to the Islamic architecture. Procedia Earth and Planetary Science, 15, 133-140.

Kaewpeela, P., Raksawin, K., \& Suthasupa, S. (2020). Identity on the Facade of Roi Et Provincial Hall. Asian Journal of Environment-Behaviour Studies, 5(15), $29-42$.

Klein, L., Li, N., \& Becerik-Gerber, B. (2012). Imaged-based verification of as-built documentation of operational buildings. Automation in Construction, 21, 161-171..

Mahayuddin, S. A., Zaharuddin, W. A. Z. W., Harun, S. N., \& Ismail, B. (2017). Assessment of building typology and construction method of traditional longhouse. Procedia engineering, 180, 1015-1023.

Kamaruzaman, N. U. S. N. (2019). HISTORIC BUILDING INFORMATION MODELLING (HBIM): A REVIEW. ICRP 2019 - 4th International Conference on Rebuilding Place. https://doi.org/10.15405/epms.2019.12.58

Russo, M., Giugliano, A. M., \& Asciutti, M. (2019). MOBILE PHONE IMAGING FOR CH FAÇADE MODELLING. The International Archives of Photogrammetry, Remote Sensing and Spatial Information Sciences, 42, 287-294.

Sabron, M. Z. M., Hashim, R., Abdullah, A., \& Shamsudin, N. (2020). Humanizing Technology: Smartphone usage in the learning environment. Environment-Behaviour Proceedings Journal, 5(13), 107-115.

Salvador-García, E., Valldecabres, J. L. G., \& Blasco, M. J. V. (2020). Integrating HBIM models in the management of the public use of heritage buildings. Canadian Journal of Civil Engineering, 47(2), 228-235

Sharif, H. M., Hazumi, H., \& Meli, R. H. (2018, January). 3D documenatation of the petalaindera: digital heritage preservation methods using 3D laser scanner and photogrammetry. In IOP Conference Series: Materials Science and Engineering (Vol. 290, No. 1, p. 012071). IOP Publishing.

Sztwiertnia, D., Ochakek, A., Tama, A., \& Lewińska, P. (2019). HBIM (heritage Building Information Modell) of the Wang Stave Church in Karpacz-Case Study. International Journal of Architectural Heritage, 1-15.

Torresani, A., \& Remondino, F. (2019). Videogrammetry VS Photogrammetry for Heritage 3d Reconstruction. 